\title{
Fructan Mobilization and the Involvement of Two $\beta$-Fructofuranosidases in Lycoris radiata Sprouting
}

\author{
Yasunori Nagamatsu, Masahito YaHata and Chitoshi Hatanaka \\ Department of Applied Biochemistry, Faculty of Applied Biological Science, \\ Hiroshima University, Higashi-Hiroshima 724, Japan \\ Received July 11, 1991
}

\begin{abstract}
Seasonal changes of oligofructans, sucrose, glucose, and fructose contents in the various tissues of Lycoris radiata were followed by HPLC analyses. Oligofructans were found in all tissues except the scape, where large and nearly equal amounts of glucose and fructose were present. At the sprouting stage, oligofructans in the bulb greatly decreased with increases of both fructose content and $\beta$-fructofuranosidase activity. The bulb enzyme responsible for the fructan breakdown was a fructan exohydrolase that was inactive against sucrose, and the scape tissue contained a $\beta$-fructofuranosidase (EC 3.2.2.26) highly active toward sucrose. These results show a role of the accumulated fructans as an energy source for sprouting of the scape during the non-photosynthetic stage, the energy probably being supplied as sucrose.
\end{abstract}

Fructans, polymers of fructose with glucose (sucrose) as an end group, are water-soluble carbohydrates, with marked diversities in size and structure among plant species. The study on the roles of fructans is a current interesting subject in plant physiology and ecology. ${ }^{1,2)}$

Lycoris radiata is a perennial monocot classified into Amaryllidacea, a family of the Liliflorae. This plant bears green leaves in the cold winter season and enters dormancy in late spring. In a previous report, ${ }^{3)}$ we showed the coexistence of 1-kestose-based and neokestosebased oligofructans in all spring tissues, in both of which the fructose chain is elongated by $\beta-2,1$ linkages. In September, the bud sprouts from the stem at the bottom of the bulb and the scape elongates rapidly, followed by flower blooming. These events are clearly separated from the progress of elongation of the regenerated leaves in October. Thus, sprouting is an aspect independent of photosynthesis. Mobilization of fructans for proceeding the development is expected; that is the subject of this study.

\section{Materials and Methods}

Materials. Whole bodies of Lycoris radiata were har- vested at Higashi-Hiroshima City on April 23, September 16, and November 1 in 1988. The plant bodies in April and November were dissected to leaf, root, bulb, and stem tissues, and those in September were to bulb, stem, root, flower (bud and claxes), scape, and lower part of scape (including small neonatal leaves) inside the bulb. Authentic l-kestose and nystose were isolated from Meioligo-P (Meiji Seiká Co., Ltd.) by gel-filtration chromatography as described previously. ${ }^{3 \text { ) }}$

Extraction, preparation, and HPLC analyses of neutral mono- and oligosaccharides. These methods were described previously. ${ }^{3 ;}$

Assay of $\beta$-fructofuranosidase activity. Assays were conducted with $2 \%$ sucrose or $3 \% 1$-kestose in $0.06 \mathrm{M}$ citrate $0.127 \mathrm{M} \mathrm{Na}_{2} \mathrm{HPO}_{4}$ buffer, $\mathrm{pH} 5.0$, at $30^{\circ} \mathrm{C}$, and the formed reducing sugars were measured by a modification of the Somogyi method. ${ }^{41}$ D-Glucose and D-fructose had the same colorimetric coefficient in this method. One enzyme unit was defined as the amount which catalyzes the hydrolysis of $1 \mu \mathrm{mol}$ of the glycosidic linkages per minute. However, the values for the scape enzyme with 1-kestose as the substrate may contain some error because the first cleavage releases one mole of reducing sugar but the second does two moles at once (see Results).

Purification of $B$-fructofuranosidases from scape and bulb tissues of September. Enzymes were extracted with $0.5 \mathrm{M}$ potassium phosphate buffer, $\mathrm{pH} 6.0$, by grinding the minced tissues with quartz powder, and extracted proteins were precipitated by back-dialysis against solid $\mathrm{NH}_{4} \mathrm{SO}_{4}$. The scape enzyme preparation after ammonium sulfate 
fractionation (30-90\% saturation) was filtered through a Sephacryl S-200 column equilibrated with $20 \mathrm{~mm}$ potassium phosphate buffer, $\mathrm{pH} 6.0$, containing $0.2 \mathrm{M}$ $\mathrm{NaCl}$, giving a single peak of $\beta$-fructofuranosidase activity. After rechromatography, the active fractions were pooled, concentrated, dialyzed against $20 \mathrm{~mm}$ Tris-

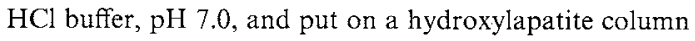
equilibrated with $5 \mathrm{~mm}$ sodium phosphate buffer, $\mathrm{pH} 6.8$. Bound proteins were eluted with a linear gradient (5-200 mm) of phosphate, and the $\beta$-fructofuranosidase activity appeared as two partially separated peaks in the range of $20-40 \mathrm{~mm}$ phosphate.

The crude bulb enzyme solution was very viscous (due to glucomannan) and was first put on a DEAE-cellulose (DEAE-Sephacel, Pharmacia) column equilibrated with

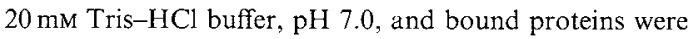
eluted with a linear gradient of Tris $(20-450 \mathrm{~mm})$. Thirteen percent of the activity appeared in the unbound fraction and the major activity was eluted as s single peak at around $90 \mathrm{~mm}$ Tris. The major enzyme was further purified by gel-filtration chromatography on a Sephacryl S-200 column, giving a single activity peak.

\section{Results and Discussion}

In the three seasons, April, September, and November, hot $70 \%$ ethanol-extractable neutral sugars from the dissected tissues of Lycoris radiata were analyzed by HPLC (Table I). Weights of a plant body varied from 10 to $70 \mathrm{~g}$. Bodies of moderate sizes were chosen for these analyses and the dissected tissues were mixed for standardization. Major oligosaccharides were oligofructans and sucrose, and glucantype oligosaccharides (maltose and maltotriose) were quite minor $(0.08-1.03 \mathrm{mg} / \mathrm{g}$ tissue) irrespective of plant parts and seasons. Only glucose and fructose were detected as neutral monosaccharide.

In April, oligofructans were found in all tissues, particularly at high concentrations in the stem and bulb tissues. The bulk (more than

Table I. Seasonal Changes of Sugar Contents in L. radiata Tissues

\begin{tabular}{|c|c|c|c|c|c|c|c|c|c|c|}
\hline & \multirow{2}{*}{ Weight (g) } & \multicolumn{2}{|c|}{ Fructose } & \multicolumn{2}{|c|}{ Glucose } & \multicolumn{2}{|c|}{ Sucrose } & \multicolumn{3}{|c|}{ Oligofructans $s^{a}$} \\
\hline & & Conc. ${ }^{b}$ & Cont. ${ }^{c}$ & Conc. & Cont. & Conc. & Cont. & Conc. & Cont. & D.P. ${ }^{d}$ \\
\hline \multicolumn{11}{|l|}{ Apr. } \\
\hline Bulb & $25.90 \pm 1.62$ & 1.26 & 95.5 & 0.48 & 36.4 & 7.75 & 587 & $>25.4$ & $>1925$ & 11 \\
\hline Stem & $0.64 \pm 0.15$ & 2.16 & 4.1 & 0.85 & 1.6 & 22.3 & 42 & $\approx 25.0$ & $\approx 48$ & 8 \\
\hline Root & $1.26 \pm 0.29$ & 5.97 & 22 & 5.86 & 22 & 15.2 & 56 & 10.9 & 40 & 6 \\
\hline \multirow[t]{2}{*}{ Leaf } & $6.37 \pm 0.74$ & 7.49 & 139 & 7.95 & 148 & 9.71 & 181 & 4.05 & 75.3 & 6 \\
\hline & $\overline{34.20 \pm 1.91}$ & & 261 & & 208 & & 886 & \multicolumn{3}{|c|}{$>\overline{2088}$} \\
\hline \multicolumn{11}{|l|}{ Sept. } \\
\hline Bulb & $18.45 \pm 1.06$ & 17.0 & 913 & 1.00 & 53.7 & 17.6 & 945 & 6.11 & 328 & 6 \\
\hline Stem & $0.53 \pm 0.04$ & 2.72 & 4.4 & 1.26 & 2.0 & 25.4 & 41 & 4.54 & 7.3 & 6 \\
\hline L. scape & $1.66 \pm 0.72$ & 9.25 & 44 & 8.82 & 42 & 15.8 & 76 & 16.2 & 78 & 5 \\
\hline Scape & $9.86 \pm 1.48$ & 14.5 & 415 & 13.7 & 392 & 1.16 & 33.2 & N.D. & N.D. & \\
\hline Flower & $1.22 \pm 0.05$ & 4.62 & 16 & 3.42 & 12 & 10.3 & 36 & 8.91 & 31 & 6 \\
\hline \multirow[t]{2}{*}{ Root } & $2.67 \pm 1.31$ & 1.10 & 8.6 & 1.10 & 8.6 & 4.18 & 33 & 1.07 & 8.3 & 4 \\
\hline & $\overline{34.38 \pm 1.83}$ & & $\overline{1401}$ & & 510 & & $1 \overline{164}$ & & 453 & \\
\hline \multicolumn{11}{|l|}{ Nov. } \\
\hline Bulb & $20.50 \pm 1.44$ & 10.2 & 605 & 0.75 & 44.5 & 8.76 & 519 & 7.60 & 451 & 7 \\
\hline Stem & $0.46 \pm 0.07$ & 2.47 & 3.2 & 1.45 & 1.9 & 11.6 & 15 & 3.12 & 4.1 & 7 \\
\hline Root & $2.74 \pm 1.10$ & 2.26 & 18 & 1.47 & 12 & 1.08 & 8.5 & 0.52 & 4.1 & 5 \\
\hline \multirow[t]{2}{*}{ Leaf } & $10.92 \pm 1.53$ & 7.95 & 250 & 9.42 & 297 & 5.77 & 182 & 1.37 & 43.2 & 4 \\
\hline & $34.70 \pm 2.35$ & & 876 & & 355 & & 725 & & $\overline{502}$ & \\
\hline
\end{tabular}

Dissected tissues from twelve plant bodies $(3 \mathrm{l}-38 \mathrm{~g})$ were mixed and homogenized, and samples equivalent to $5-20 \mathrm{~g}$ tissues were used for preparation of neutral sugars. The standard deviations of HPLC analyses ( 3 times for each sample) were less than $5 \%$ for the monosaccharides and surcrose and less than $10 \%$ for oligofructans.

a Oligofructans up to heptamer were quantified by HPLC.

${ }^{b} \mathrm{mg} / \mathrm{g}$ tissue.

c mg/l00g plant body.

¿ Maximum degree of polymerization detected by TLC.

N.D., not detected. 
$92 \%$ ) of fructans was stored in the bulb, the heaviest tissue in this season. The concentrations of monosaccharides were high in root and leaf tissues where nearly equal amounts of fructose and glucose were found. Sucrose concentrations in the stem were always the highest among those in the plant parts.

During the elongation of the scape tissue in September, the fructan content in the bulb greatly decreased with decreasing degrees of polymerization. The sucrose and fructose concentrations in the bulb increased 2.3- and 13-fold, respectively. In the stem tissue, the fructan concentration also decreased but no great increase of the monosaccharides was observed. A high level of sucrose concentration was kept in this season. The scape tissue contained large and nearly equal quantities of

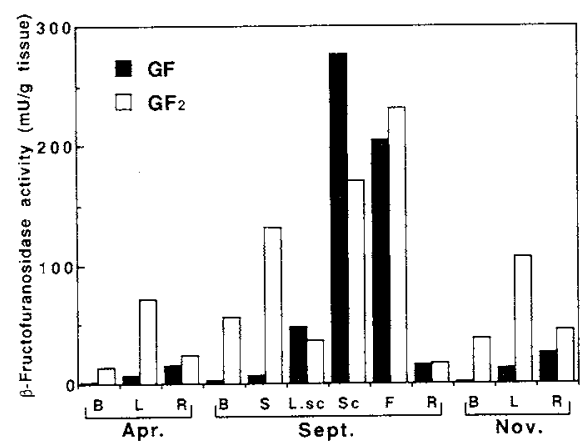

Fig. 1. Seasonal Changes of Sucrose (GF) and 1Kestose $\left(\mathrm{GF}_{2}\right)$ Hydrolase Activities in the Tissues of Lycoris radiata.

B, bulb; L, leaf; R, root; S, stem; L.sc, lower part of scape; Sc, scape; F, flower (bud and claxes).

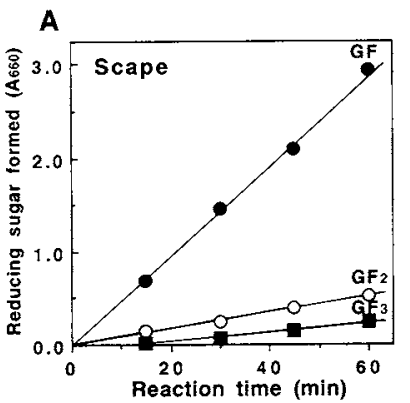

fructose and glucose but oligofructans were not detected. The flower (bud and claxes) tissue contained oligofructans in addition to the monosaccharides and sucrose. At the beginning of November, new leaves elongated and oligofructans increased in the bulb tissue with increasing of the degree of polymerization.

The fact that all tissues except the scape contain oligofructans indicates multiple functions of these in this plant. The decrease of bulb fructans in September suggests their mobilization as an energy source for elongation of the scape. So, the enzyme activities for fructan breakdown were measured with two substrates, sucrose and 1-kestose, in each tissue of the three seasons (Fig. 1). Activities toward 1-kestose in the bulb and stem tissues increased in September, in accord with the fructan breakdown in this season. Relative activities against the two substrates varied among the tissues and were divided into two types. The scape and flower tissues had high activities toward both substrates and the activity in root belonged to the same type, although its activity was low. In contrast, the bulb, stem, and leaf tissues showed much higher activities against 1-kestose than those toward sucrose. These facts indicate the presence of at least two types of $\beta$-fructofuranosidase in L. radiata.

The enzymes in the bulb and scape tissues were partially purified and characterized. The scape enzyme for sucrose hydrolysis was

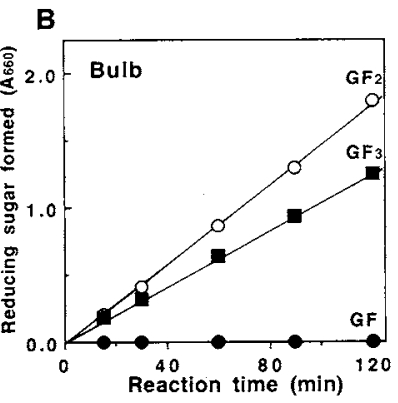

Fig. 2. Hydrolysis Activities toward Sucrose (GF, 2\%), 1-Kestose $\left(\mathrm{GF}_{2}, 3 \%\right)$ and Nystose $\left(\mathrm{GF}_{3}, 4 \%\right)$ of the Partially Purified Scape (A) and Bulb (B) Enzymes.

Reactions were done at $\mathrm{pH} 5.0$ and $30^{\circ} \mathrm{C}$ with the scape enzyme $(26 \mathrm{mU} / \mathrm{mi}, 6.4 \mu \mathrm{g}$ protein/ml $)$ or with the bulb enzyme $(15 \mathrm{mU} / \mathrm{ml}, 255 \mu \mathrm{g}$ protein $/ \mathrm{ml})$. 
purified 50 -fold by ammonium sulfate precipitation, gel-filtration, and hydroxylapatite chromatography (data not shown). The bulb enzyme for 1-kestose hydrolysis was purified 7-fold by DEAE-cellulose and gel-filtration chromatography. The bulb contained a minor $(13 \%)$ activity component that was not bound to DEAE-cellulose at $\mathrm{pH} 7.0$, but the enzymatic properties were virtually the same as those of the major one as will be described

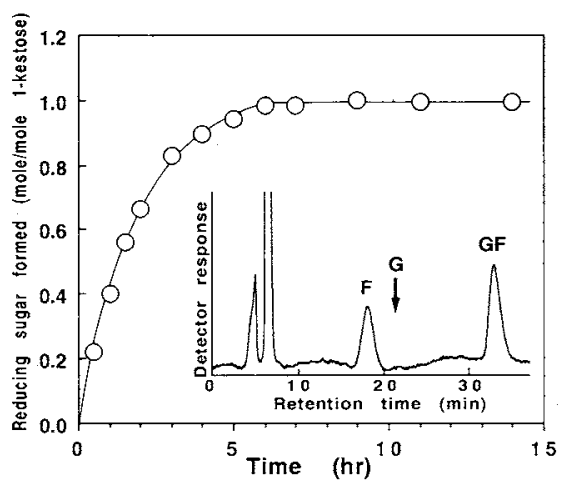

Fig. 3. Hydrolysis of 1-Kestose with the Bulb Enzyme and Product Analysis by HPLC (the Insert).

1-Ketose $(0.08 \%)$ was hydrolyzed with the partially purified bulb enzyme $(24 \mathrm{mU} / \mathrm{ml})$ at $\mathrm{pH} 5.0$ and $30^{\circ} \mathrm{C}$. The progress of the reaction was followed by a modification of the Somogyi method. ${ }^{4)}$ HPLC analysis was done with a sample from a 14 -hr reaction after removal of proteins by passing through a MolCut II LGC (NMWL 10,000, Millipore) filter and salts by ion-exchange chromatography. ${ }^{3)} \mathrm{F}$, fructose; $\mathrm{G}$, glucose; $\mathrm{GF}$, sucrose.

Table II. Characteristics of $\beta$-Fructofuranosidases FROM $L$. radiata SCAPE AND BULB TISSUES

\begin{tabular}{lll}
\hline & Scape enz. & Bulb enz. \\
\hline Specificity & $\mathrm{G}_{\bar{\uparrow}} \mathrm{F}_{\bar{\uparrow}} \mathrm{F}_{\bar{\uparrow}} \mathrm{F}$ & $\mathrm{G}_{-}-\mathrm{F}_{\bar{\uparrow}} \mathrm{F}_{\bar{\uparrow}} \mathrm{F}$ \\
Opt. pH & 5.0 & \\
pH stability & $5.0-6.5$ & 5.0 \\
$\mathrm{Km}^{a}$ & $8.2 \mathrm{mM}(\mathrm{GF})$ & $4.0-6.5$ \\
$V_{\max }{ }^{b}$ & $4.63(\mathrm{GF})$ & $0.0624\left(\mathrm{GF}_{2}\right)$ \\
M.W. $^{c}$ & 51,000 & 68,000 \\
\hline
\end{tabular}

$\mathrm{G}$, glucose; F, fructose; GF, sucrose; $\mathrm{GF}_{2}$, 1-kestose.

a At pH 5.0 and $30^{\circ} \mathrm{C}$.

${ }^{b} \mu \mathrm{mol} / \mathrm{min} / \mathrm{mg}$ enzyme. The enzymes used were partially purified.

c Measured by gel-filtration chromatography on a Sephacryl S-200 column. later: The scape enzyme hydrolyzed either sucrose or oligofructans (Fig. 2A). During the hydrolysis of nystose, HPLC analysis showed 1-kestose, sucrose, fructose and glucose as the products but not fructose trimer or dimer. Fructose dimer was not found either in the reaction mixture with 1-kestose. These results indicate that the scape enzyme is a $\beta$-fructofuranosidase (EC 3.2.2.26) and not a kind of inulinase. The rate of hydrolysis of glucose1,2-fructose linkage in sucrose (half of the rate of increase of reducing sugars) was at least 2.8 times higher than that of the $\beta$-2,1-linkage between fructose residues in 1-Kestose. In contrast to the scape enzyme, the major bulb enzyme did not hydrolyze sucrose at all (Fig. 2B). When reacted thoroughly with 1 -kestose, one mole of reducing sugar was generated from one of the substrate, and the products were sucrose and fructose (Fig. 3). So, the major bulb enzyme can not cleave the glucose1,2-fructose linkage in 1-kestose. The minor bulb enzyme hydrolyzes 1 -kestose and nystose at a similar rate but not sucrose as well as the major one. Several other properties of the scape and the major bulb enzymes were summarized in Table II.

From the seasonal changes of sugar constitutions and $\beta$-fructofuranosidase activities in the tissues of Lycoris radiata, it is clear that sucrose and fructose generated through the breakdown of bulb fructans in September are used as energy for the scape elongation. The bulb enzyme responsible for the breakdown of fructans was a $\beta$-fructofuranosidase, which removed fructose residues from terminals of oligofructans but was inactive for sucrose. Enzymes of this type have been isolated from tubers of Helianthus tuberosus ${ }^{5}$ and tap roots of Taraxacum officinale ${ }^{6)}$ and those are called fructan exohydrolase. Fructan exohydrolase activities have also been detected in Festuca arundinacea, ${ }^{7)}$ Allium cepa, ${ }^{8)}$ and Dactylis glomerata. ${ }^{9)}$ Hydrolysis of small oligofructans may proceed in the stem tissue, considering its high enzyme activity of the same type (Fig. 1). Although the transportation process of energy was not examined in 
this study, it is thought that a majority of the energy is sent in the form of sucrose molecules to the scape tissue through the stem tissue because the stem tissue always has high concentrations of sucrose and the scape tissue has a very high activity of sucrose hydrolysis. The concentrations of glucose and fructose were quite high and approximately equimolar in the scape tissue, indicating rapid sucrose hydrolysis in the tissue. Mobilization of fructans was reported on sprouting of the tubers of Helianthus tuberosus in spring. ${ }^{10,11)}$ In the tubers, rapid conversion of ${ }^{14} \mathrm{C}$-fructose to sucrose through fructose-6-phosphate, glucose6-phosphate, and uridine diphosphate glucose was observed. Sucrose is also important as substrate for fructan synthesis. ${ }^{12,13)}$ In Lycoris radiata, however, a possibility of other transportation forms such as small oligofructans has not yet been excluded, taking into consideration for the high 1-kestose hydrolysis activity in the scape tissue. The lower part of the scape (including small neonatal leaves) and the bud (including claxes) contained appreciable amounts of oligofructans, suggesting some physiological functions of the sugar other than storage of energy and materials for cellular metabolism. The functions may not be compensated by sucrose. These remain to be elucidated.

\section{References}

I) C. J. Nelson and W. G. Spollen, Physiologia Plantarum, 71, 512 (1987).

2) C. J. Pollock and N. J. Chatterton, The Biochemistry of Plants, 14, 109 (1988).

3) Y. Nagamatsu, M. Yahata, T. Fukada and C. Hatanaka, Agric. Biol. Chem., 54, 1291 (1990).

4) C. Hatanaka and Y. Kobara, Agric. Biol. Chem., 44, 2943 (1980).

5) J. Edelman and T. G. Jefford, Biochem. J., 93, 148 (1964)

6) P. P. Rutherford and A. C. Deacon, Biochem. J., 126, 569 (1972).

7) A. E. Smith, J. Agric. Food. Chem., 24, 476 (1976).

8) R. J. Henry and B. Darbyshire, Plant Science Lett., 14, 155 (1979).

9) S. Yamamoto and Y. Mino, Plant Physiol., 78, 591 (1985).

10) J. Edelman and T. G. Jefford, New Phytol., 67, 517 (1968).

11) M. Frehner, F. Keller, A. Wiemken and P. Matile, J. Plant Physiol., 116, 197 (1984).

12) C. J. Pollock, New Phytol., 104, 1 (1986).

13) N. Shiomi, Carbohydr. Res., 96, 281 (1981). 